\title{
Combined Serum DKK3 and Circulating CDI33 Cells as Prognostic Biomarkers for Ovarian Cancer Patients
}

This article was published in the following Dove Press journal: OncoTargets and Therapy

\author{
Xiao-Cui Nie' \\ Fang $\mathrm{He}^{\prime}$ \\ Chong Lan' \\ Ju-Min Niu' \\ $\mathrm{Pu} \mathrm{Xia}\left(\mathbb{D}^{2}\right.$
}

'Department of Gynaecology, Shenyang Women's and Children's Hospital, Shenyang, Liaoning, People's Republic of China; ${ }^{2}$ Biological Anthropology Institute, Liaoning Medical University, Jinzhou, Liaoning, People's Republic of China
Correspondence: Pu Xia Biological Anthropology Institute, Liaoning Medical University, Jinzhou, Liaoning, People's Republic of China Emailnn001007@I63.com
Introduction: Ovarian cancer $(\mathrm{OV})$ can seriously endanger women's physical and mental health. Serum DKK3 has been used for the diagnosis and prognosis of patients with ovarian cancer. However, the specificity of antibodies may lead to errors in the detection of plasma protein.

Methods: Circulating $\mathrm{CD}_{133^{+}}$cells from blood samples were separated by magnetic microbeads. Serum DKK3 levels were determined by ELISA. The roles of DKK3 in OV cells were analyzed in vitro.

Results: In this study, we found that the $\mathrm{CD}_{133^{+}}$subpopulation in circulating tumor cells can indicate the overall survival rate of OV patients. Serum DKK3 levels were negatively correlated with the number of circulating $\mathrm{CD} 133^{+}$cells in OV patients. In addition, we confirmed the inhibitory effect of recombinant human DKK3 (rhDKK3) on OV cells via reversal of the epithelial-mesenchymal transition (EMT) process.

Conclusion: Both serum DKK3 levels and circulating CD133 $3^{+}$tumor cells can be used as prognostic markers for patients with ovarian cancer.

Keywords: DKK3, ovarian cancer, CD133, Wnt, prognosis

\section{Introduction}

Many methods have been used for the clinical diagnosis of cancer. ${ }^{1}$ Tissue biopsy is more reliable than other methods, but it carries a high risk for patients. ${ }^{1}$ Some imaging examination methods (eg, CT and MRI) have the advantages of non-invasive and accurate positioning; however, the evaluation of the results mainly depends on clinical experience and anatomical knowledge. ${ }^{2,3}$ Therefore, serum markers are suitable for improving the diagnostic efficiency and safety for cancer patients.

Circulating tumor cells (CTCs) are all kinds of tumor cells existing in peripheral blood. ${ }^{4}$ Tumor cells invade the blood and lymphatic system, form CTCs, and are transported to the distal tissue. ${ }^{5}$ The early detection of CTCs in the blood has significance in making prognostic judgments, evaluation of the curative effect, and individualized treatment. ${ }^{6}$ CD133 is a glycoprotein expressed on hematopoietic progenitors and has been widely used in sorting cancer stem cells (CSCs). ${ }^{7}$ Circulating $\mathrm{CD} 33^{+}$cells are prognostic and diagnostic markers for colorectal cancer and gastric cancer. ${ }^{8,9}$

The DKK family consists of DKK1, DKK2, DKK3, and DKK4, which modulate the Wnt signaling pathway. ${ }^{10}$ Abnormal expression of DKK1, DKK2, DKK3, or DKK4 proteins leads to malignant tumors. ${ }^{11}$ The Wnt signaling pathway is 
a basic pathway involved in embryonic development and adult tissue homeostasis. ${ }^{12}$ Secretory inhibitors, such as DKK3, inhibit the Wnt signaling pathway by competitively binding to the LRP5/6 receptor. ${ }^{13}$ Epithelial ovarian cancer (EOC) is the leading cause of death among all gynecological cancers. ${ }^{14}$ Serum DKK3 is a diagnostic marker for ovarian cancer. ${ }^{15}$ In this study, we compared the serum levels of DKK3 with the numbers of CD133 cells in ovarian cancer (OV) patients and healthy volunteers. We found that serum DKK3 and circulating CD133 ${ }^{+}$ cells can be used as prognostic markers for patients with ovarian cancer.

\section{Materials and Methods Bioinformatic Analysis}

Gene Expression Profiling Interactive Analysis (GEPIA, http://gepia.cancer-pku.cn/) is a newly developed interactive server to analyze cancer and normal gene expression profiling based on data from TCGA (https://tcga-data.nci.nih.gov/ tcga/) and the Genotype-Tissue Expression project (https:// www.gtexportal.org/home/index.html). ${ }^{16}$ We explored the relative expression of DKK1, DKK2, DKK3, and DKK4 via GEPIA based on the clinicopathological features of OV. The mutations and copy numbers of DKK3 in all kinds of cancer patients were calculated using the cBioPortal online database (www.cbioportal.org). ${ }^{17}$

\section{Blood Samples}

Blood samples were obtained from 167 patients who had not received any chemotherapy or radiotherapy prior to complete resection at the Department of Gynaecology, Shenyang Women's and Children's Hospital, between July 2010 and July 2015. All patients provided written informed consent. Control blood samples were obtained from 40 healthy volunteers. The volunteers were female and of similar ages to the patients. This study was conducted according to the principles expressed in the Helsinki Declaration of 1975 and approved by the Ethics Committee of Liaoning Medical University.

\section{Serum DKK3 Levels}

Enzyme-linked immunosorbent assay (ELISA) was used to detect the DKK3 levels in OV patients. The human DKK3 ELISA kit was purchased from R\&D Systems (Shanghai, China). According to the manufacturer's protocol, the optical density was measured at $450 \mathrm{~nm}$.

\section{Sorting and Identify Circulating $\mathrm{CDI} 33^{+}$ Cells}

As in our previous method, circulating $\mathrm{CD} 133^{+}$cells from blood samples were separated by magnetic microbeads. ${ }^{9}$ The purity of sorted cells was evaluated using flow cytometry (Becton Dickinson, San Jose, CA). Cells were stained with fluorescently labeled CD133-FITC (Thermo Fisher, Shanghai, China) to identify CD133 expression and DAPI to identify nucleated cells.

\section{MTT Assay}

Recombinant human DKK3 (rhDKK3) was purchased from R\&D Systems (Shanghai, China). CD133 ${ }^{+}$cells or CD133- cells were plated in $96-$-well plates ( 1000 cells per well). After $24 \mathrm{~h}$, cells were treated with various concentrations of rhDKK3 (eg, 0, 5, 10, 15, 20, 25, $30 \mu \mathrm{g} / \mathrm{mL}$ for each). The MTT Cell Proliferation and Cytotoxicity Assay Kit was purchased from Beyotime Biotechnology (Shanghai, China). At the end of the treatment period (48 h), $20 \mu \mathrm{L}$ of MTT solution was added to each well. After incubation for $4 \mathrm{~h}$ at $37^{\circ} \mathrm{C}$, absorbance density values were checked at $570 \mathrm{~nm}$ to determine the cell viability.

\section{Quantitative Real-Time PCR}

Quantitative real-time PCR (qPCR) was used to measure the changes in epithelial-mesenchymal transition (EMT). Total RNA was extracted from cells using TRIzol reagent (Invitrogen, Shanghai, China). cDNA was synthesized using the PrimeScript ${ }^{\mathrm{TM}}$ RT Reagent Kit (Takara, Dalian, China). qPCR was carried out using the SYBR Green PCR Mix Kit (Takara) according to the instructions. The results were analyzed using the $\Delta \Delta \mathrm{CT}$ (cycle threshold) method. The primers used in this study are summarized in Table 1.

\section{Western Blot Analysis}

Cells were washed once with PBS, and lysed for $30 \mathrm{~min}$ in lysis buffer (50 mM Tris- $\mathrm{HCl} \mathrm{pH} 7.5,150 \mathrm{mM} \mathrm{NaCl}$, $1 \%$ Nonidet P-40) containing protease inhibitors (Cocktail; Roche, Basel, Switzerland) and phosphatase inhibitors $\left(1 \mathrm{mM} \mathrm{NaF}\right.$ and $\left.1 \mathrm{mM} \mathrm{Na}_{3} \mathrm{VO}_{4}\right)$. The lysates were centrifuged at $15,000 \times \mathrm{g}$ at $4^{\circ} \mathrm{C}$ for $15 \mathrm{~min}$. Total cell lysate proteins were separated using 10\% SDSPAGE and transferred to nitrocellulose (NC) membranes (KeyGen, Nanjing, China). The NC membranes were incubated with primary antibodies overnight at $4^{\circ} \mathrm{C}$, including E-cadherin (sc-8426), N-cadherin (sc-59,987), Vimentin (sc-6260), Snail (sc-271,977), and GAPDH 
Table I Relationship Between Serum DKK3 or Circulating CDI33+ Tumor Cells and Clinicopathological Parameters of OV Patients

\begin{tabular}{|c|c|c|c|c|c|c|c|c|c|}
\hline \multirow[t]{2}{*}{ Clinicopathological Features } & \multicolumn{5}{|c|}{ sDKK3 } & \multicolumn{4}{|c|}{$\mathrm{CD} / 33^{+}$} \\
\hline & $\mathbf{n}$ & Low & High & $\chi^{2}$ & $P$ & $\leq 3$ & $>3$ & $\chi^{2}$ & $P$ \\
\hline Age (years) & & & & 13.4 & 0.00025 & & & 0.13 & 0.713 \\
\hline$<50$ & 83 & 44 & 39 & & & 14 & 69 & & \\
\hline$\geq 50$ & 84 & 67 & 17 & & & 16 & 68 & & \\
\hline Venous invasion & & & & 7.93 & 0.0048 & & & 16.1 & 0.00006 \\
\hline- & 73 & 40 & 33 & & & 23 & 50 & & \\
\hline+ & 94 & 71 & 23 & & & 7 & 87 & & \\
\hline Lymphatic invasion & & & & 4.09 & 0.0431 & & & 0.15 & 0.690 \\
\hline- & 89 & 53 & 36 & & & 15 & 74 & & \\
\hline+ & 78 & 58 & 20 & & & 15 & 63 & & \\
\hline Preoperative CAI25 (U/mL) & & & & 0.88 & $0.347 \mid$ & & & 2.31 & 0.128 \\
\hline$<600$ & 65 & 46 & 19 & & & 8 & 57 & & \\
\hline$\geq 600$ & 102 & 65 & 37 & & & 22 & 80 & & \\
\hline Histological grade & & & & 2.25 & 0.324 & & & 1.52 & 0.468 \\
\hline Grade I & 44 & 33 & 11 & & & 8 & 36 & & \\
\hline Grade 2 & 81 & 50 & 31 & & & 12 & 69 & & \\
\hline Grade 3 & 42 & 28 & 14 & & & 10 & 32 & & \\
\hline Residual tumor & & & & 0.14 & 0.700 & & & 5.15 & 0.0231 \\
\hline$<1 \mathrm{~cm}$ & 80 & 52 & 28 & & & 20 & 60 & & \\
\hline$\geq 1 \mathrm{~cm}$ & 87 & 59 & 28 & & & 10 & 77 & & \\
\hline FIGO stage & & & & 2.80 & 0.423 & & & 11.38 & 0.0098 \\
\hline I & 27 & 19 & 8 & & & 10 & 17 & & \\
\hline II & 48 & 35 & 13 & & & 8 & 40 & & \\
\hline III & 68 & 44 & 24 & & & 6 & 62 & & \\
\hline IV & 24 & 13 & 11 & & & 6 & 18 & & \\
\hline
\end{tabular}

Abbreviation: $\chi^{2}$, Chi-squared distribution.

(sc-47,724) (Santa Cruz, CA, USA). Each specific antibody binding was detected with horseradish peroxidase (HRP)-conjugated respective secondary antibodies (Beyotime Biotechnology, Beijing, China). Bands were visualized using the ECL Western Blotting Analysis System (Amersham Biosciences, Piscataway, NJ).

\section{Statistical Analysis}

Statistical evaluation was performed using the Spearman correlation test to analyze rank data and using the MannWhitney $U$-test and Student's $t$-test to differentiate the means of the different groups. A Kaplan-Meier survival analysis was performed to obtain the survival curves. $P$-values of $<0.05$ were considered to indicate statistical significance. GraphPad Prism 5 software (GraphPad Software, San Diego, CA) was used to analyze all data.
Results

\section{$D K K 1, D K K 2, D K K 3$, and $D K K 4$ in OV}

\section{Tissues}

Based on the GEPIA analysis of cancer vs normal tissue, we found that DKK3 mRNA was significantly lower in the OV tissues than that in normal tissues (Figure 1A). DKK1, DKK2, and DKK4 showed no significant difference in OV tissues and normal tissues (Figure $1 \mathrm{~A})$. We also did not find any differences in $D K K 1, D K K 2, D K K 3$, or $D K K 4$ mRNA in different stages of OV (Figure 1B). Kaplan-Meier analysis revealed that $D K K 1, D K K 2, D K K 3$, and $D K K 4 \mathrm{mRNA}$ were not correlated with the overall survival rate or the disease-free survival rate of $\mathrm{OV}$ patients $(P>0.05)$ (Figure $1 \mathrm{C}$ and $\mathrm{D}$ ). Genetic alteration rates for $\mathrm{OV}$ patients were less than $2 \%$ (Figure 1E). 

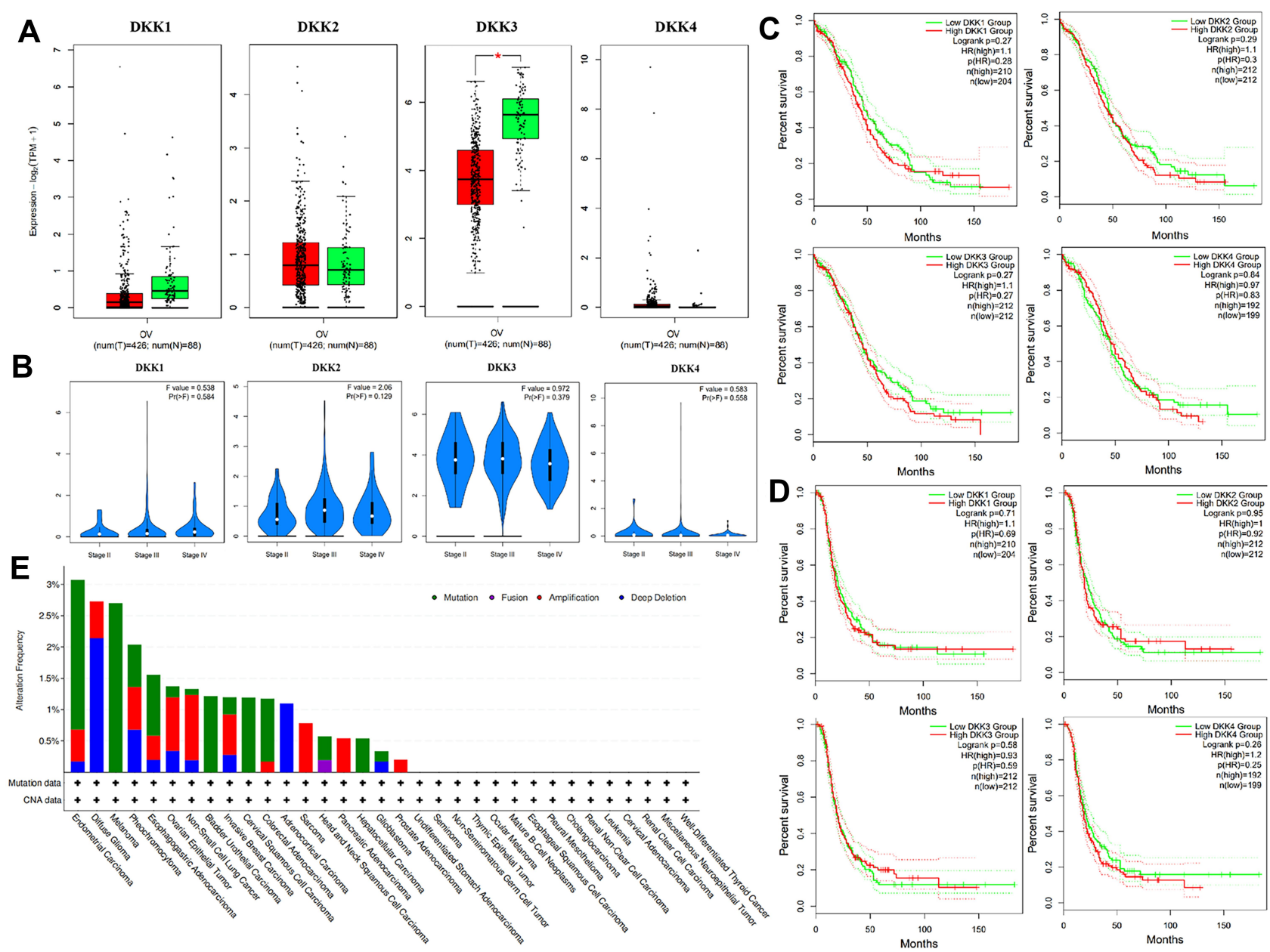

Figure I Bioinformatic analysis of DKKI-4 mRNA in OV patients. (A) DKKI-4 mRNA was evaluated in cancer tissues and matched normal tissues of the OV patients using GEPIA $(* P<0.05)$. (B) DKKI-4 mRNA in different stages was evaluated using GEPIA. (C) Overall survival analysis and (D) disease-free survival analysis of DKKI-4 in OV patients were performed using GEPIA. (E) The mutations and copy numbers of DKK3 in all kinds of cancer patients were calculated using the cBioPortal online database.

\section{Circulating CDI $33^{+}$Cells and Serum DKK3 from OV Patients}

Circulating $\mathrm{CD} 133^{+}$cells were isolated from blood samples $(7 \mathrm{~mL})$ of $\mathrm{OV}$ patients using magnetic microbeads and counted using flow cytometry (Figure 2A). Immunofluorescence confirmed CD133 expression in $\mathrm{CD}_{133^{+}}$cells (Figure $2 \mathrm{~A}$ ). In OV patients, the number of circulating $\mathrm{CD} 133^{+}$cells was higher than that in healthy control individuals $(P<0.05)$ (Figure 2B). Serum DKK3 levels in the 167 patients ranged from $34 \mathrm{pg} / \mathrm{mL}$ to $102 \mathrm{pg} / \mathrm{mL}$, with a median of $56 \mathrm{pg} / \mathrm{mL}(P<0.05)$ (Figure $2 \mathrm{C}$ ). The sDKK3 levels were negatively correlated with the number of circulating $\mathrm{CD} 133^{+}$cells in these patients $(r=-0.9453)(P<0.05)$ (Figure 2D). The overall survival rate of the patients with high sDKK3 levels was higher than that of those with low levels $(P<0.05)$ (Figure 2E). Patients with three or fewer
CTCs lived longer than those ones with more than three CTCs $(P<0.0)$ (Figure 2F). As shown in Table 2, CD133 ${ }^{+}$ cells were associated with venous invasion $(P=0.00006)$, residual tumor $(P=0.0231)$, and FIGO stage $(P=0.0098)$. In addition, sDKK3 was associated with age ( $P=0.00025)$, lymphatic invasion $(P=0.0431)$, and venous invasion $(P=0.0048)$.

\section{Role and Mechanism of rhDkk3 in CDI $33^{+}$Cells}

The proliferation ratio of both $\mathrm{CD} 133^{+}$and $\mathrm{CD} 133^{-}$cells was inhibited by rhDkk3, as evidenced by the MTT assay $(P<0.05)$ (Figure 3A). However, Dkk3 inhibited the $\mathrm{CD}_{133}{ }^{+}$cells more obviously $(P<0.05)$ (Figure $3 \mathrm{~A}$ ). Furthermore, we found that the mRNA levels of $\mathrm{N}$-cadherin, Vimentin, and Snail were decreased significantly with DKK3 treatment, while E-cadherin increased 
A

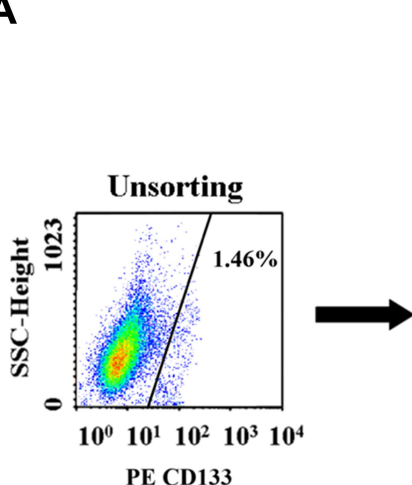

PE CD133
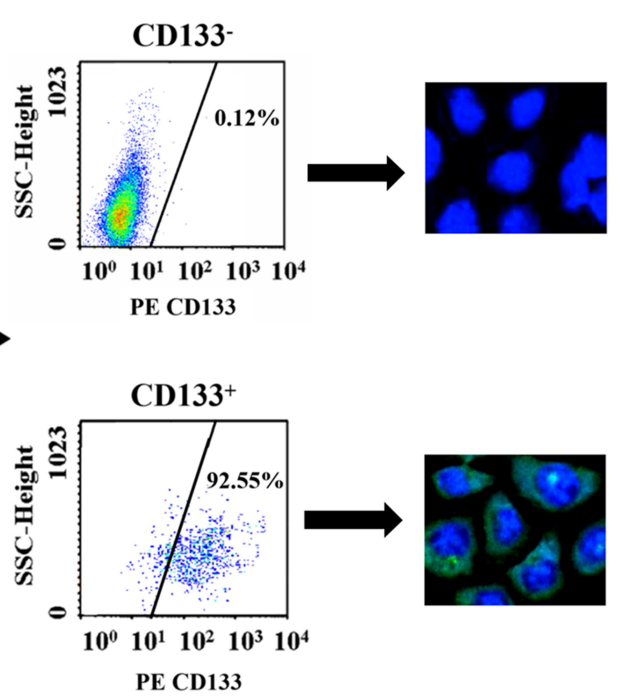

B

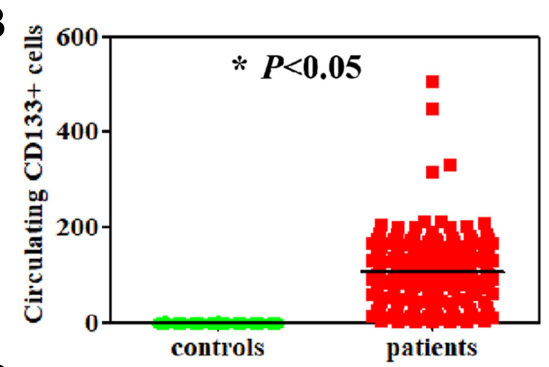

C

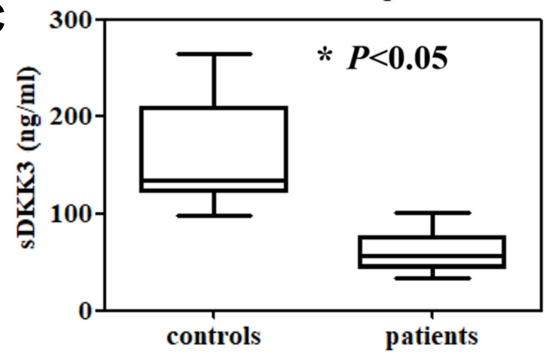

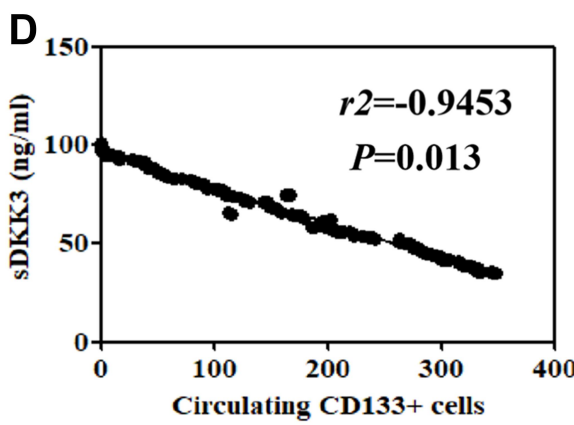
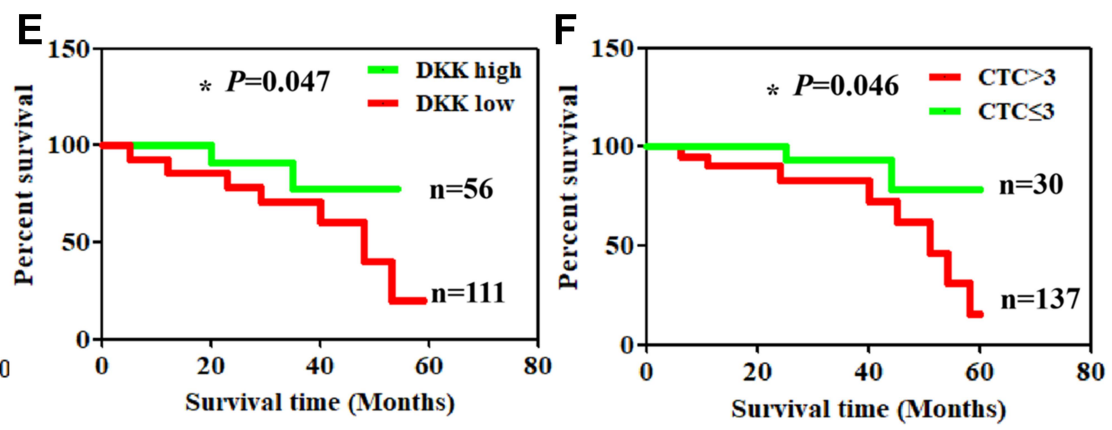

Figure 2 Circulating $\mathrm{CDI} 33^{+}$cells and sDKK3 in OV patients' blood samples. (A) Distribution of CDI $33^{+}$and $\mathrm{CDI} 33^{-}$cells was detected by flow cytometry. IF was used to identify the cells. (B) The number of circulating $C D I 33^{+}$cells was determined using FCM in patients and healthy controls ( $n=3, P<0.05$, vs control group). (C) Serum levels of DKK 3 in patients and healthy controls were evaluated by ELISA ( $n=3, P<0.05$, vs control group). (D) Correlation between sDKK3 and circulating CDI $33^{+}$cell levels was evaluated using the Spearman correlation test $\left(r^{2}=-0.9453, P=0.013\right)$. (E) Kaplan-Meier survival analysis was performed in the OV patients with high or low sDKK3 levels $(P=0.047)$. (F) Kaplan-Meier survival analysis was performed in the OV patients with different numbers of circulating $C D \mid 33^{+}$cells $(P=0.046)$.

in the two cell types $(P<0.05)$ (Figure 3B). The changes in $\mathrm{N}$-cadherin, Vimentin, Snail, and E-cadherin proteins in OV cells with DKK3 treatment were consistent with their mRNA levels $(P<0.05)$ (Figure 3C). Pan-cancer analysis generated an overview of the mechanism for all DKK family members in OV (Figure 3D).

Table 2 List of Real-Time PCR Primers

\begin{tabular}{|l|l|}
\hline Gene-Specific Primer & Sequence (5' to $\mathbf{3}^{\prime}$ ) \\
\hline E-cadherin forward & TCGACACCCGATTCAAAGTGG \\
E-cadherin reverse & TTCCAGAAACGGAGGCCTGAT \\
N-cadherin forward & TGAGCCTGAAGCCAACCTTA \\
N-cadherin reverse & AGGTCCCCTGGAGTTTTCTG \\
Vimentin forward & GAGAACTTTGCCGTTGAAGC \\
Vimentin reverse & GCTTCCTGTAGGTGGCAATC \\
Snail forward & CCATGCTCCTCTTTGCTCTC \\
Snail reverse & TACAAAAACCCACGCAGACA \\
GAPDH forward & AAGAAGGTGGTGAAGCAGGC \\
GAPDH reverse & GTCAAAGGTGGAGGAGTGGG \\
\hline
\end{tabular}

\section{Discussion}

Low DKK3 expression in the tissue and serum of patients with OV has been confirmed. ${ }^{18,19}$ In this study, we analyzed the mRNA levels of members of the DKK family in OV tissues using TCGA database, and found lower $D K K 3$ levels in cancer tissues than in normal tissues. These results are consistent with a previous study. ${ }^{19}$ Although CTCs are diagnostic and prognostic markers for OV patients, ${ }^{19}$ in this study, we found a subgroup of CTCs. We isolated the circulating $\mathrm{CD}_{133^{+}}$ cells from $\mathrm{OV}$ patients. No $\mathrm{CD}_{13}{ }^{+}$cells were observed in healthy volunteers. So, circulating $\mathrm{CD} 133^{+}$cells could be used as a diagnostic and prognostic marker for OV patients. The main finding of this study is the negative correlation between serum DKK3 level and circulating CD133 ${ }^{+}$cells in OV. Both markers can indicate the prognosis of $\mathrm{OV}$ patients. The target specificity of antibodies may lead to errors in the detection of plasma proteins. ${ }^{20}$ Our results show that a combination of the two markers could provide a reliable prognosis for $\mathrm{OV}$ patients. 


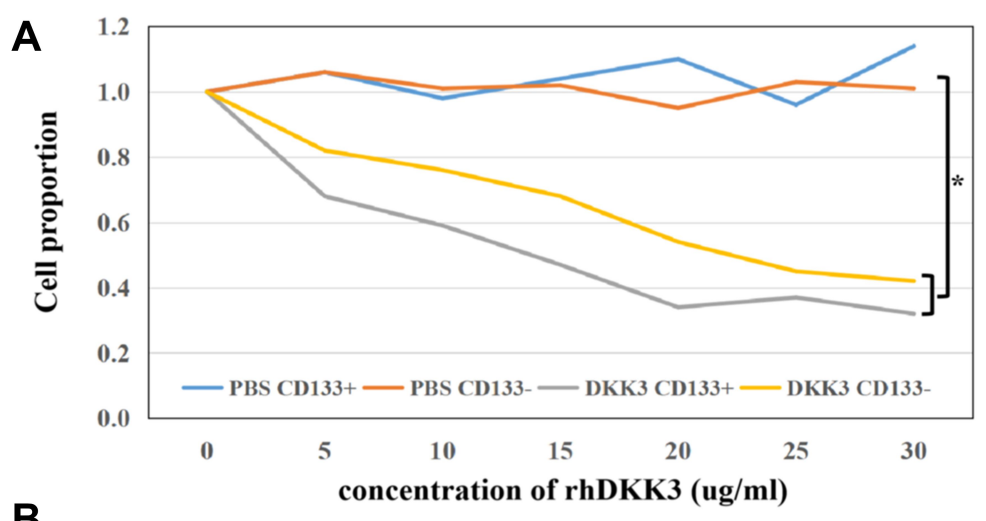

B

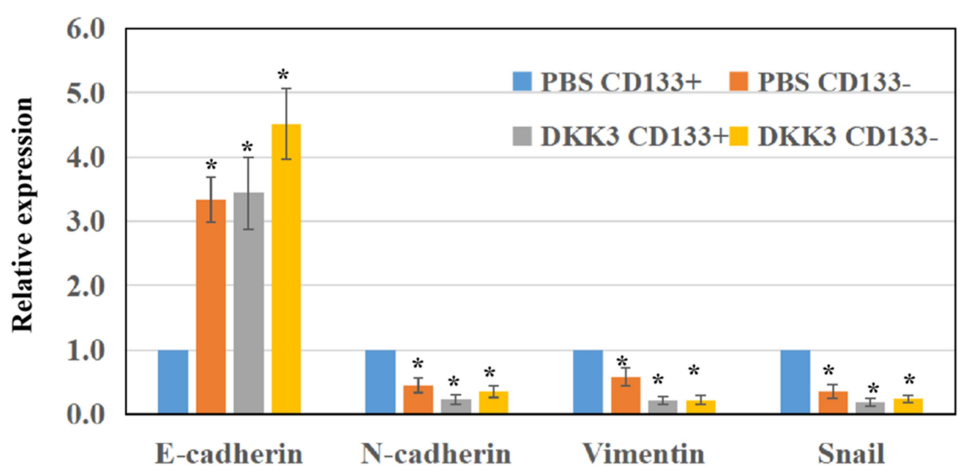

C

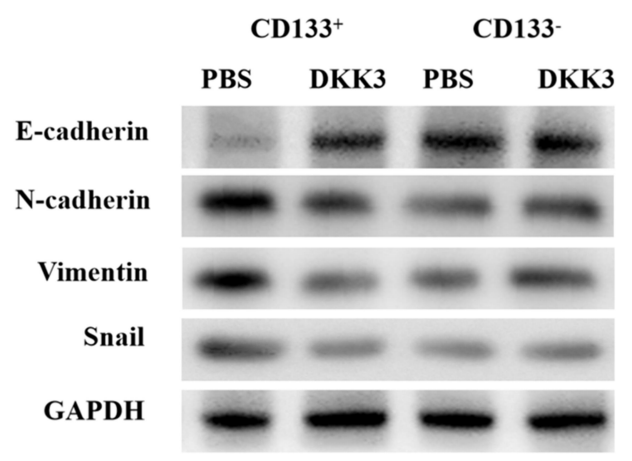

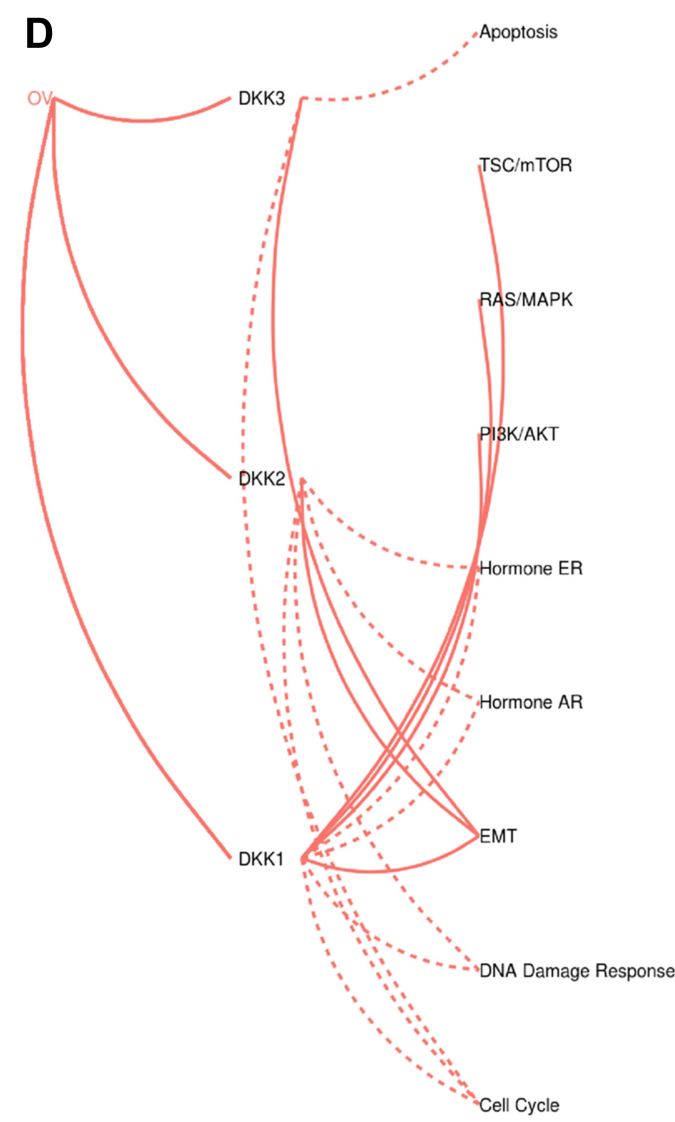

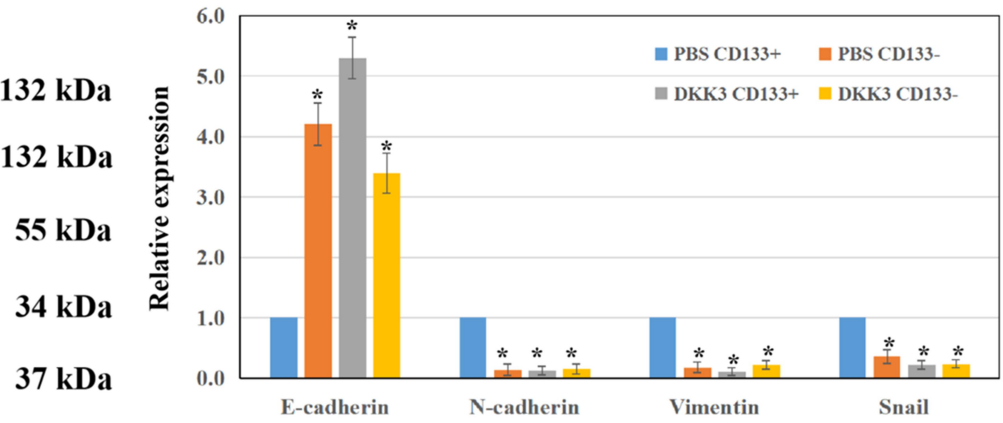

Figure 3 The anti-tumor roles of DKK3 in $\mathrm{CDI} 33^{+}$cells in vitro. (A) The proliferation rate of cells was determined by $M T T$ assay $\left(n=3\right.$, $* P<0.05$, vs PBS CDI $33^{+}$group). $(\mathbf{B})$ qPCR was used to check the changes in the EMT pathway $\left(n=3, * P<0.05\right.$, vs PBS CDI $33^{+}$group). (C) Western blot was used to check the changes in the EMT pathway ( $=3$, $* P<0.05$, vs PBS CDI $33^{+}$group). GAPDH was used as the internal control. (D) The mechanism of DKKI-4 in OV was analyzed using GEPIA.

In vitro, we confirmed the inhibitory effect of rhDKK3 on $\mathrm{CD} 133^{+}$cancer cells. With regard to the mechanism, Western blot and real-time PCR results showed an increase in the epithelial marker E-cadherin and reduced mesenchymal markers (Vimentin, N-cadherin, and Snail) after DKK3 treatment. All the evidence showed that DKK3 reversed the EMT process in $\mathrm{CD}_{133^{+}}$cells. EMT is related to tumor progression and drug resistance. ${ }^{21}$ DKK3 is an inhibitor of the Wnt pathway. ${ }^{10}$ Nuclear translocation of $\beta$-catenin promotes EMT in OV cells. ${ }^{22}$ Lu et al ${ }^{23}$ showed that curcumin can inhibit the progress of EMT by regulating the WNT signaling pathway. Pan-cancer analysis also showed that
DKK3 could regulate EMT in OV. However, analysis of the results suggests that DKK3 can also regulate the cell cycle and apoptosis via other pathways. This provides us with future research directions. In our previous study, the interaction of DKK3 and CD133 was confirmed. ${ }^{24}$ This partly explains the stronger inhibitory effect of DKK3 on $\mathrm{CD}_{133^{+}}$cells than on $\mathrm{CD} 133^{-}$cells.

In this study, we confirmed the negative correlation between serum DKK3 and circulating $\mathrm{CD}_{13}{ }^{+}$cells in OV patients. Both markers can be used for predicting the outcome of OV patients. In addition, DKK3 played an anti-tumor role in OV cells by reversing EMT. 


\section{Author Contributions}

All authors made substantial contributions to conception and design, acquisition of data, or analysis and interpretation of data; took part in drafting the article or revising it critically for important intellectual content; agreed to submit to the current journal; gave final approval of the version to be published; and agree to be accountable for all aspects of the work.

\section{Funding}

This study was supported by the Natural Science Foundation of Liaoning Province (grant nos. 2019-ZD -0984).

\section{Disclosure}

Xiao-Cui Nie and Fang He report grants from the Natural Science Foundation of Liaoning Province, during the conduct of the study and outside the submitted work. The authors declare that they have no other potential conflicts of interest for this work.

\section{References}

1. Zhou Y, Abel GA, Hamilton W. Diagnosis of cancer as an emergency: a critical review of current evidence. Nat Rev Clin Oncol. 2017;14:45-56. doi:10.1038/nrclinonc.2016.155

2. Abel G, Saunders CL, Mendonca SC, Gildea C, McPhail S, Lyratzopoulos G. Variation and statistical reliability of publicly reported primary care diagnostic activity indicators for cancer: a cross-sectional ecological study of routine data. BMJ Qual Saf. 2018;27:21-30. doi:10.1136/bmjqs-2017-006607

3. Bottle A, Tsang C, Parsons C, Majeed A, Soljak M, Aylin P. Association between patient and general practice characteristics and unplanned first-time admissions for cancer: observational study. $\mathrm{Br}$ J Cancer. 2012;107:1213-1219. doi:10.1038/bjc.2012.320

4. Liskova A, Samec M, Koklesova L, Giordano FA, Kubatka P, Golubnitschaja O. Liquid biopsy is instrumental for 3PM dimensional solutions in cancer management. $J$ Clin Med. 2020;9:E2749. doi:10.3390/jcm9092749

5. Zeeshan R, Mutahir Z. Cancer metastasis - tricks of the trade. Bosn J Basic Med Sci. 2017;17:172-182. doi:10.17305/bjbms.2017.1908

6. Allard WJ, Matera J, Miller MC. Tumor cells circulate in the peripheral blood of all major carcinomas but not in healthy subjects or patients with nonmalignant diseases. Clin Cancer Res. 2004;10:6897-6904. doi:10.1158/1078-0432.CCR-04-0378

7. Pilati $\mathrm{P}$, Mocellin S, Bertazza L, et al. Prognostic value of putative circulating cancer stem cells in patients undergoing hepatic resection for colorectal liver metastasis. Ann Surg Oncol. 2012;19:402-408. doi:10.1245/s10434-011-2132-2
8. Gibbs CP, Kukekov VG, Reith JD, et al. Stem-like cells in bone sarcomas: implications for tumorigenesis. Neoplasia. 2005;7:967-976. doi:10.1593/neo.05394

9. Xia P, Song CL, Liu JF, Wang D, Xu XY. Prognostic value of circulating $\mathrm{CD} 133(+)$ cells in patients with gastric cancer. Cell Prolif. 2015;48:311-317. doi:10.1111/cpr.12175

10. Niehrs C. Function and biological roles of the Dickkopf family of Wnt modulators. Oncogene. 2006;25:7469-7481. doi:10.1038/sj. onc. 1210054

11. Moon RT, Kohn AD, De Ferrari GV, Kaykas A. WNT and beta-catenin signalling: diseases and therapies. Nat Rev Genet. 2004;5:691-701. doi:10.1038/nrg1427

12. Hayes M, Naito M, Daulat A, Angers S, Ciruna B. Ptk7 promotes non-canonical Wnt/PCP-mediated morphogenesis and inhibits Wnt/ $\beta$-catenin-dependent cell fate decisions during vertebrate development. Development. 2013;140:1807-1818. doi:10.1242/dev.090183

13. Baetta R, Banfi C. Dkk (Dickkopf) proteins. Arterioscler Thromb Vasc Biol. 2019;39:1330-1342. doi:10.1161/ATVBAHA.119.312612

14. Lheureux S, Braunstein M, Oza AM. Epithelial ovarian cancer: evolution of management in the era of precision medicine. $C A$ Cancer J Clin. 2019;69:280-304. doi:10.3322/caac.21559

15. Jiang T, Huang L, Wang S, Zhang S. Clinical significance of serum Dkk-3 in patients with gynecological cancer. J Obstet Gynaecol Res. 2010;36:769-773. doi:10.1111/j.1447-0756.2010.01234.x

16. Tang Z, Li C, Kang B, Gao G, Li C, Zhang Z. GEPIA: a web server for cancer and normal gene expression profiling and interactive analyses. Nucleic Acids Res. 2017;4:W98-W102. doi:10.1093/nar/ gkx247

17. Gao J, Aksoy BA, Dogrusoz U, et al. Integrative analysis of complex cancer genomics and clinical profiles using the cBioPortal. Sci Signal. 2013;6:11. doi:10.1126/scisignal.2004088

18. You A, Fokas E, Wang LF, et al. Expression of the Wnt antagonist DKK3 is frequently suppressed in sporadic epithelial ovarian cancer. $J$ Cancer Res Clin Oncol. 2011;137:621-627. doi:10.1007/s00432010-0916-6

19. Rao Q, Zhang Q, Zheng C, et al. Detection of circulating tumour cells in patients with epithelial ovarian cancer by a microfluidic system. Int J Clin Exp Pathol. 2017;10:9599-9606.

20. Sharon B. A western blot and immunoprecipitation assay to verify antibody specificity. BioTechniques. 2015;59:168-169.

21. Goossens S, Vandamme N, Van Vlierberghe P, Berx G. EMT transcription factors in cancer development re-evaluated: beyond EMT and MET. Biochim Biophys Acta Rev Cancer. 2017;1868:584-591. doi:10.1016/j.bbcan.2017.06.006

22. Dong $\mathrm{P}, \mathrm{Fu} \mathrm{H}$, Chen $\mathrm{L}$, et al. PCNP promotes ovarian cancer progression by accelerating $\beta$-catenin nuclear accumulation and triggering EMT transition. $J$ Cell Mol Med. 2020;24:8221-8235. doi: $10.1111 / \mathrm{jcmm} .15491$

23. Lu Y, Zhang R, Zhang X, Zhang B, Yao Q. Curcumin may reverse 5 -fluorouracil resistance on colonic cancer cells by regulating TET1-NKD-Wnt signal pathway to inhibit the EMT progress. Biomed Pharmacother. 2020;129:110381. doi:10.1016/j. biopha.2020.110381

24. Xia P, Xu XY. DKK3 attenuates the cytotoxic effect of natural killer cells on $\mathrm{CD} 133+$ gastric cancer cells. Mol Carcinog. 2017;56:1712-1721. doi:10.1002/mc.22628 


\section{Publish your work in this journal}

OncoTargets and Therapy is an international, peer-reviewed, open access journal focusing on the pathological basis of all cancers, potential targets for therapy and treatment protocols employed to improve the management of cancer patients. The journal also focuses on the impact of management programs and new therapeutic agents and protocols on patient perspectives such as quality of life, adherence and satisfaction. The manuscript management system is completely online and includes a very quick and fair peer-review system, which is all easy to use. Visit http://www.dovepress.com/ testimonials.php to read real quotes from published authors.

Submit your manuscript here: https:/www.dovepress.com/oncotargets-and-therapy-journal 